\title{
Design and Implementation of Sugarcane Growth Monitoring System based on RFID and ZigBee
}

\author{
https://doi.org/10.3991/ijoe.v14i03.8413 \\ Li Biqing, Ling Yongfa \\ Hezhou University, Hezhou Guangxi, China \\ Tian Miao $(\bowtie)$ \\ Henan University, Kaifeng Henan, China \\ $229292710 @ q q . c o m$ \\ Zheng Shiyong \\ Wuhan University, Wuhan, China
}

\begin{abstract}
Sugarcane is a kind of important sugar crops, which has been planted in large area of southern China, but traditional manual operation still applied on sugarcane planting and management at present, leading to higher labor costs. In recent years, the development of Internet of Things technologies such as wireless sensor technology, ZigBee, RFID, etc., as well as the application of technologies such as video image processing, automatic control, and $3 \mathrm{~S}$, etc. have provided technical supports for precision planting of agricultural production, visual management, and intelligent decision-making. This paper, relying on the Internet of things technology, has designed and implemented a set of sugarcane growth monitoring system according to the growth characteristics of sugarcane crops, this system has passed the test, and results showed that it can effectively monitor growing environment of sugarcane, such as temperature, humidity, crop plant height, thus realize the whole process management of agricultural automation.
\end{abstract}

Keywords-RFID; agricultural automation; sugarcane; growth monitoring

\section{Introduction}

With the development of information industry in recent years, agriculture in our country has transformed from extensive form to refine, systematic form. "Intelligent agriculture", proposed in "13th Five-Year", has realized the simplified operation of agricultural production, cost reduction, process visible and controllable by using Internet of Things technology. Sugarcane is an important sugar crops in China and has been planted in large area of southern China, it is the major income source of sugarcane growers. This paper designed and implemented a set of sugarcane growth monitoring system based on RIDF and ZigBee, this system can be used for network moni- 
toring through Internet network monitoring, and implement real-time monitoring by relying on the Internet of Things technology and video image processing technology.

\section{Overview of intelligent agriculture and Internet of Things}

\subsection{A brief introduction to intelligent agriculture and technology}

"Intelligent agriculture" is the result of traditional agriculture injected element of the information age, by using the related technology of Internet of things to implement real-time monitoring, collection and analysis of agricultural information. Through the Internet of things technologies such as wireless sensor technology, ZigBee, RFID, etc., combined with technologies such as video image processing, automatic control, and $3 \mathrm{~S}$, etc., this system has provided technical supports for precision planting of agricultural production, visual management, and intelligent decisionmaking. For example, the collection of all kinds of parameters of growing environment (concentration of carbon dioxide, nitrogen, soil PH, temperature and humidity, light intensity, etc.) can be achieved by a large number of sensor nodes in the aspect of cultivation of the collection, by big data analysis on the collected parameters, environment can be automatically regulated, such as cooling, fertilization, humidity changes. The system can real-time show the growing states of crops more intuitive with advance video image and image processing technology introduced from European and American countries. Intelligent agriculture not only improves the production efficiency, will also completely reform the structure system of agricultural production to the sales.

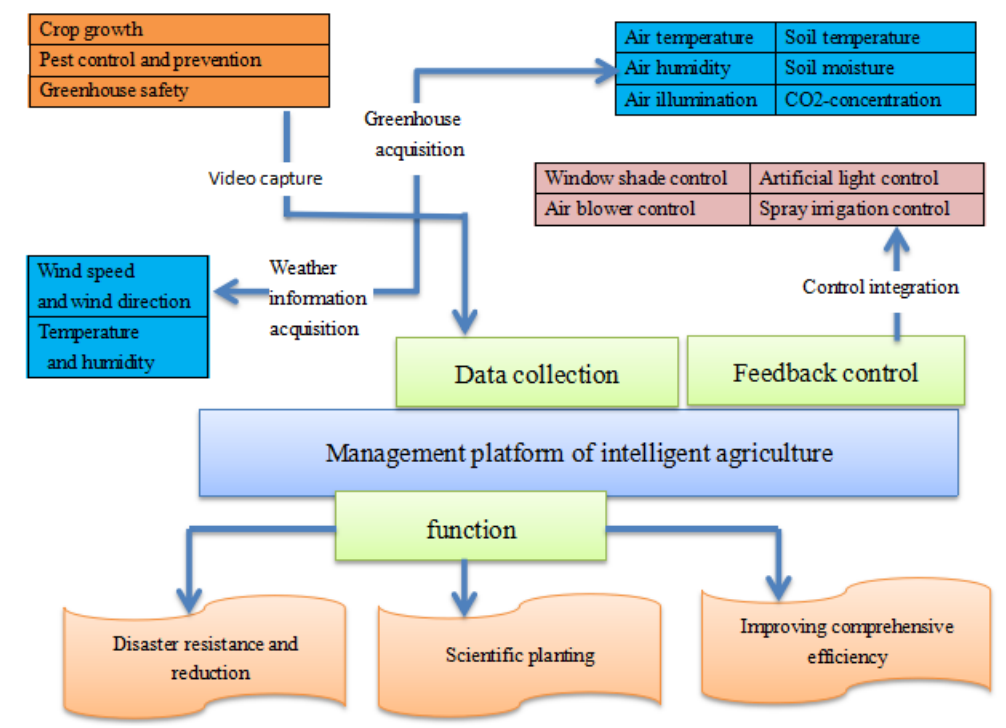

Fig. 1. The Intelligent detection system schematic diagram of intelligent greenhouse based on IOT 


\subsection{The application of Internet of Things in intelligent agriculture}

Internet of Things technology is mainly applied in planting as well as the preservation of agricultural products, therefore grower can collect the data of crop growing environment, growing states during these processes through the wireless sensor technology. First the data will be sent to management center through the network transmission, second the data will be undertaken big data computation analysis, and achieve the refine remote control finally. Internet of Things includes three layers: perception layer, transport layer and application layer. Perception layer realizes communication, energy, environmental perception mainly through sensors, video, RFID, which are mainly used for data acquisition and environmental monitoring; transport layer sends the collected data of sensor back to background data management center mainly through the application of WLAN network, 4G networks, etc.; application layer implements analysis and summary to data through big data and cloud computing, to realize detection, data storage, data management, and automation control. The framework diagram of intelligent agriculture control system based on Internet of Things frame is shown in figure 2 below. The application of "Intelligent agriculture" has transformed the traditional extensive agriculture to refine form, such transformation can avoid the waste of necessary production costs, thus save time, manpower and material resources, reduce the pollution of land and water resources, therefore produce more ecological and environmental agricultural products, the application of Internet of Things technology in the agricultural industrial chain is the sign of integration of information and agricultural modernization, which has directed a scientific development path for the development of modern agriculture in China and laid the foundation for sustainable development of agriculture based on Internet of Things in the future.

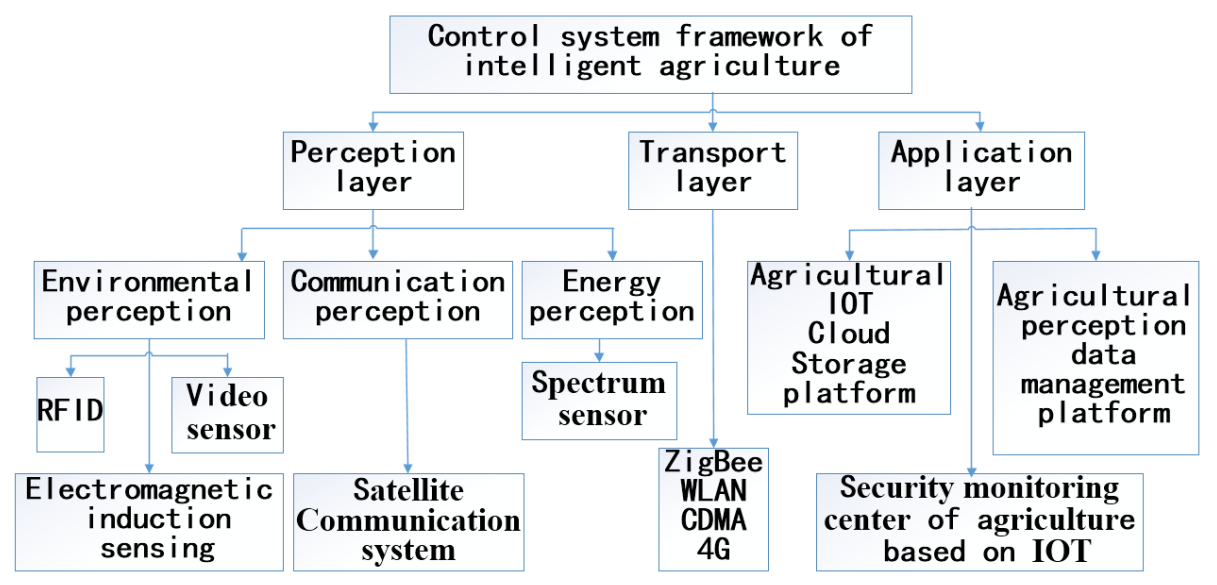

Fig. 2. Framework diagram of control system of intelligent agriculture based on IOT 


\section{$3 \quad$ Monitoring test and method of sugarcane growth}

\subsection{Experimental design}

We have done experiment in sugarcane planting area of efficient ecological experimental base in order to track and collect sugarcane growing data. We have analyzed the influence of parameters (planting area, environmental factors) to sugarcane growth in experiment, then effectively predicted the experimental results based on data. In experiment, the transport layer conducted data transmission through ZigBee, $4 \mathrm{G}$ network, perception layer mainly used all kinds of sensors (carbon dioxide sensor, image sensor, temperature sensor, photosensitive sensor, humidity sensor, etc.) to collect data, predict data collection and data transmission, thus provided powerful evidence for the effectiveness of the experimental results.

In order to guarantee the validity of the experiment, it will randomly select a monitoring area in planting base before planting, the size of monitoring area generally is $2 \mathrm{~m} \times 2 \mathrm{~m}$, after the monitoring area selected, insert indicating poles in the four corners of area, place a bench-marking pole to identify monitoring center in monitoring area, install a binocular camera in front of pole for image data collection, send data to background management control center at 10 AM each day in sugarcane growth cycle.

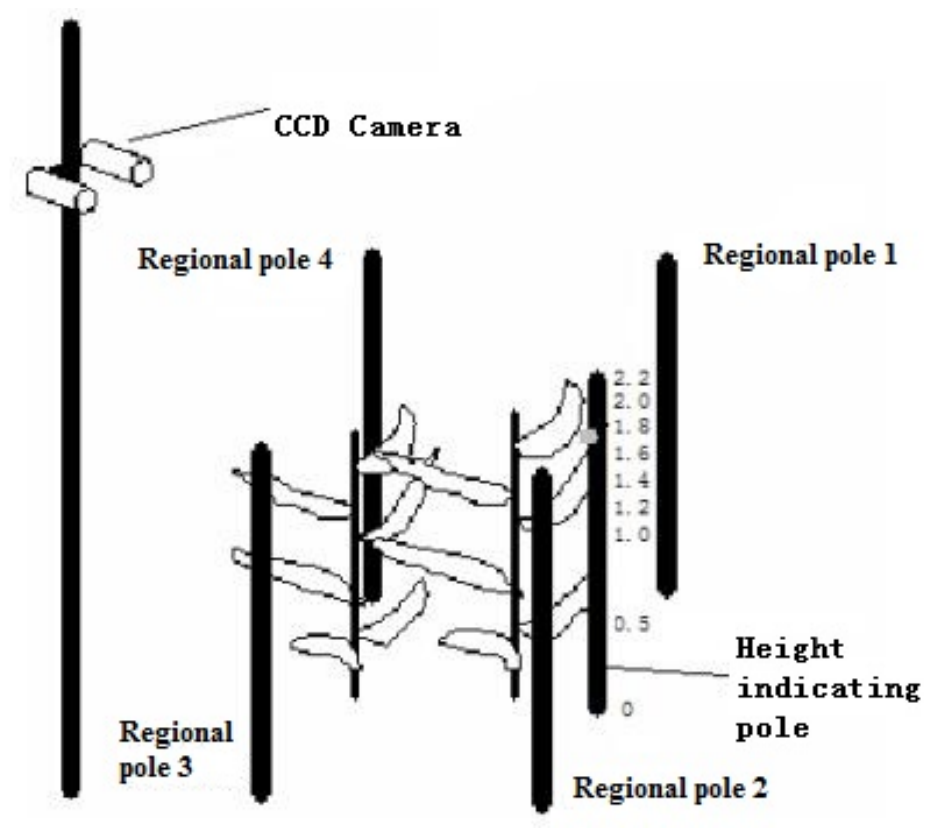

Fig. 3. Sugarcane growth height monitoring diagram 


\subsection{Real-time image acquisition method of sugarcane growth}

Video module. Speed XT core is generally used in European and American countries, which can help CCD camera to restore image effectively, reduce the color difference, make the picture appear more real gorgeous; in order to facilitate the data transmission and connection, using usb2.0 interface; at the same time can solve the sample positioning problem without the staggered influence, this module has obvious advantages in mobile object analysis. According to the request of the experiment and binocular vision positioning principle, we adopted double CCD camera for image collection of benchmarking region, two cameras should be in the same height in the process of data collection, parallel to the optical axis, the monitoring area is selected in experimental field after fully testing according to the experimental requirements.

The image information collected by double CCD camera will be transmitted to the background of management center finally. But before this, we will use the video decoder to do simple pretreatment on collected information and then segment color of the image to obtain binarization image, and then transmit the information to the backstage management center for data processing. Video module operation framework is shown in figure 4.

Sensor module. Iot technology in agricultural applications, the sensor network plays a huge role, in the whole experiment, has a pivotal position.Mainly applied in perception layer, main effect is to data collection, the planting area of temperature, humidity, illumination, soil PH, concentration of carbon dioxide, and so on data acquisition, sensor data acquisition terminal equipment, which is the sensor distribution in monitoring area.

The data collected by various functions of sensors distributed in monitoring area will be delivered step by step along the level of nodes, data information is finally converged to the network nodes, and then be transmitted to remote backstage manager via ZigBee, $4 \mathrm{G}$ network communication module on transport layer, and the sugarcane growth data will be analyzed.

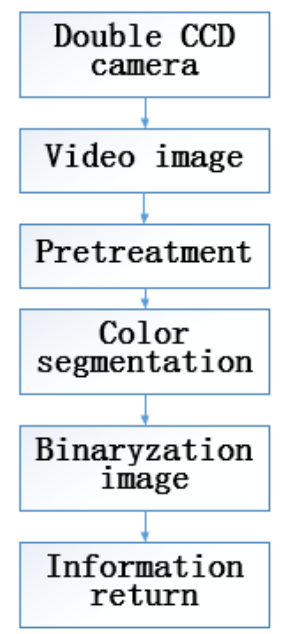

Fig. 4. Video module running framework 


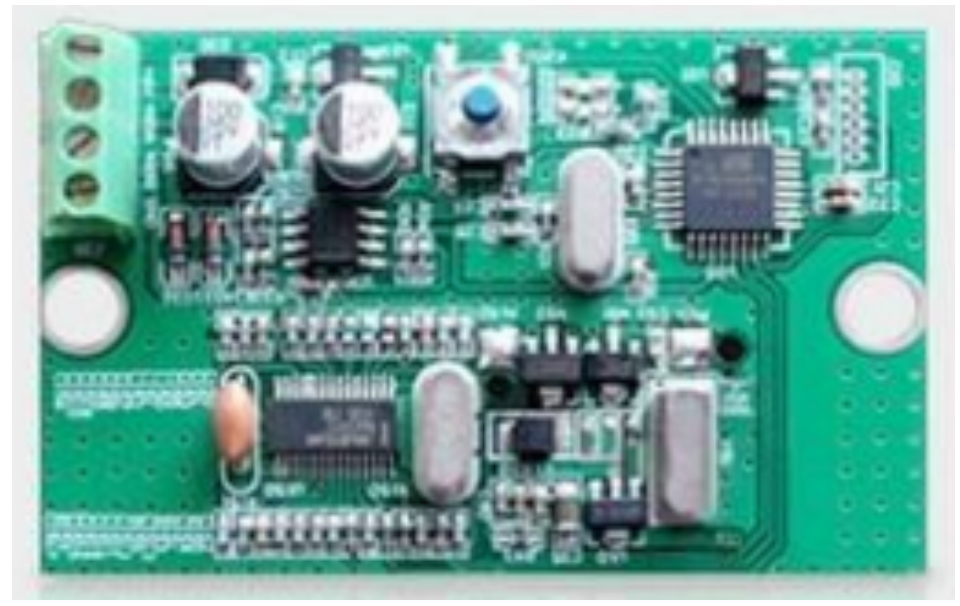

Fig. 5. Communication module diagram

Communication module. The wireless communication module plans to adopt SM50 series micropower wireless data transmission module with technical designs as micro system control, disconnection detection and modular design, the transmission power range of SM50 module: $10 \mathrm{~mW} \sim 1 \mathrm{~W}$; communication frequency is ISM frequency, carrier frequency is $433 \mathrm{MHZ}$; in GFSK modulation, SM50 can realize low error rate of precision communication even under strong noise interference, and the expansion of the channel space is larger, on the basis of standard configuration, user may need to do channel expansion, the extension extremum of channel number is up to 116 . In addition, hardware is the combination design of integrated circuit and single chip MCU, peripheral circuit is less, so the occurrence of failure is less. Communication module is shown in figure 5.

\subsection{Field measurement of sugarcane plant height}

Sugarcane sowing is generally in spring, sugarcane growth in seedling stage, but due to the climate, the sugarcane may not be suffered severe disaster during April to May, rain is abundant and sugarcane grows well during the period, but should pay attention to weeding. Two or three months starting in June, this period is the golden stage of sugarcane growth, the temperature of sugarcane production field is generally high, sunshine duration is long, humidity is larger in this period, these conditions are very suitable for the growth of the sugarcane, so it is the best period for sugarcane fertilizer absorption, growing, and elongating, so the fertilizer utilization ratio will reach the largest in this period. Next stage is from September to November, this stage is the sugar accumulation of sugarcane, because the larger of temperature difference between day and night, the faster the sugar accumulation will be. In order to fully understand the sugarcane plant growing states in different growth periods, we will conduct data collection and analysis in several different periods of sugarcane in our experiment. 
When measuring, we will use a portable measuring instrument, the maximum range of measuring instrument is $4 \mathrm{~m}$, can basically satisfy the requirement of sugarcane length measurement. The measuring instrument can obtain sugarcane plant height data within $1 \mathrm{~s}$, and the measuring instrument can undertake corresponding autonomic regulation according to the environment, so the measurement error caused by weather, sunshine, and temperature is reduced. Using visual technology, the camera can get image of the measuring instrument directly, and do corresponding algorithm calculation to obtain further sugarcane plant height data. Plant height data obtained from real-time measurement can be transmitted to background data management platform through network transmission. The average of plant height in each growth cycle can be determined through data analysis and calculation, compared with sugarcane plant height data obtained by double CCD camera, find the error value of both. Confirmatory experiments have verified the scientificity and real effectiveness of the collected data, which indicates the reliability of the measuring video module.

\section{Systematic design for sugarcane growth monitoring analysis}

The basic system framework of the Internet of Things including perception layer, transport layer, and application layer, and the sugarcane growth monitoring and analysis system designed by this framework also includes these three layers. Perception layer mainly collects and monitors the sugarcane plant growth, the ambient environment data (temperature and humidity, sunshine, $\mathrm{CO} 2$, etc.) through sensors, video, RFID; transport layer sends the collected data mainly through the application of Internet, WiFi, network management, realizes the linking of application layer and perception layer; application layer implements analysis and summary to data, realize the client data detection and storage, according to industry demands, this layer can apply the intelligent Internet of Things. The system uses unified communication protocol, data interface and information sharing protocol conforming to the standard of agriculture based on Internet of Things, which has integrated the real-time perception of sugarcane growth information collection and control of equipment. The system framework is shown in figure 6 . 


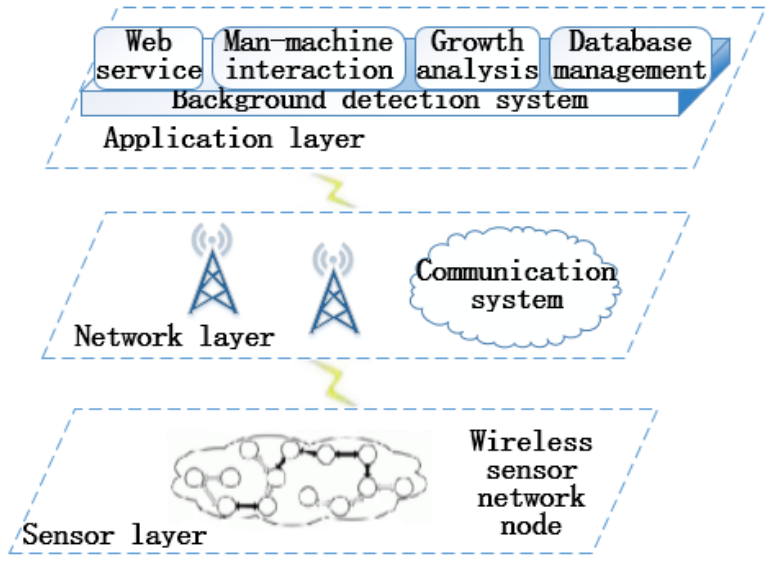

Fig. 6. Sugarcane growth monitoring analysis system framework

\section{$5 \quad$ Experimental results and analysis}

This experiment has selected one month from three periods of sugarcane growing to do real-time monitoring data collection. The mainly data collected in the system include temperature and humidity, sunshine, $\mathrm{CO} 2$, as well as to plant growth height. The actual measured plant height is analyzed with video measurement analysis data by using the portable measuring instrument, Monitoring and management system needs to use big data analysis technology to do data analysis more efficiently due to long test period, large amount of data. The effective image information can be captured through double CCD camera, as shown in figure 7, the actual measurement area is marked red.

Origin is a professional drawing and data processing tools, which can effectively improve the efficiency of data import, transformation, data processing, drawing, and data analysis. In experimental process, using this software to compare the collected environmental data and sugarcane plant height, the results are shown in Table 1 below.

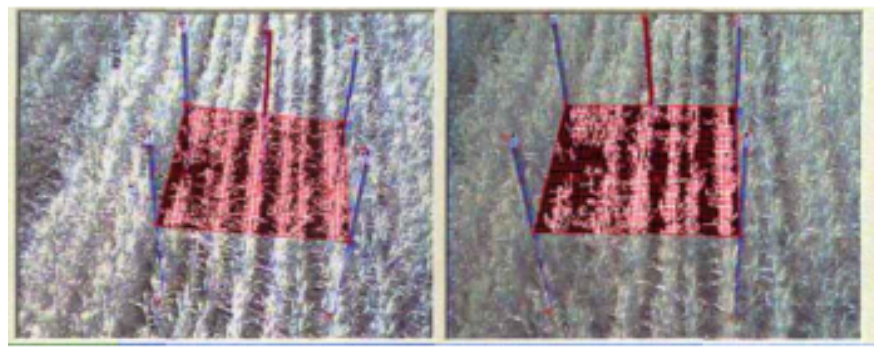

Fig. 7. Images shot by double cameras 
Table 1. Analysis of sugarcane plant height and environmental factors

\begin{tabular}{cccccc}
\hline $\begin{array}{c}\text { Period after } \\
\text { planting } \\
\text { (days) }\end{array}$ & $\begin{array}{c}\text { Temperature } \\
\left({ }^{\circ} \mathbf{C}\right)\end{array}$ & $\begin{array}{c}\text { Radiation } \\
\left(\mathbf{w} / \mathbf{m}^{\mathbf{2}}\right)\end{array}$ & $\begin{array}{c}\text { soil moisture } \\
\text { content } \\
\mathbf{( 1 \% )}\end{array}$ & $\begin{array}{c}\text { system meas- } \\
\text { ured crop } \\
\text { height } \\
(\mathbf{c m})\end{array}$ & $\begin{array}{c}\text { actual meas- } \\
\text { ured crop } \\
\text { height } \\
(\mathbf{c m})\end{array}$ \\
\hline 1 & 18 & 319 & 15.7 & 0 & 0 \\
30 & 19 & 364 & 12.5 & 10.5 & 10 \\
60 & 23 & 326 & 14.7 & 60 & 58 \\
90 & 26 & 386 & 11.8 & 98 & 101 \\
120 & 30 & 416 & 9.95 & 153 & 152 \\
150 & 31 & 427 & 9.52 & 201 & 203 \\
180 & 30 & 461 & 8.92 & 269 & 267 \\
210 & 29 & 412 & 10.5 & 308 & 305 \\
240 & 28 & 452 & 9.41 & 312 & 310 \\
240 & 26 & 432 & 9.32 & 313 & 311 \\
\hline
\end{tabular}

It can be known from above table that, the actual measured height of sugarcane plant has a probable $0 \sim 3 \mathrm{~cm}$ error with the video measured value, which indicates the experiment data collection has a higher accuracy, and the objective of accuracy requirement of experiment on data has achieved. Now the sugarcane growth monitoring system has realized the real-time remote monitoring by using visualization module (video image processing technology), as well as the in-time comprehensive comparison and analysis of data collected by sensors, the system can realize independent operation based on experimental results. So to speak, the refine, intelligent remote control of agricultural production has initially implemented. Sugarcane monitoring system, by using the Internet network connection, sensing technology of Internet of Things and the advanced image processing technology, can real-time master crop growth and the latest growing environment by login the system. Through multiple data comparisons, it can also find out the accurate optimal growth environment of crops, as well as the golden period of growth, so as to improve crop yield and maximize the economic benefit.

\section{Conclusion}

The development of modern agriculture is an effective way to solve the problem of a large population with relatively little land in our country. The use of Internet of Things technology in agriculture is a symbol of the process of agricultural modernization. In recent years, the application and improvement of technologies in the Internet of things on agriculture, including wireless sensor, wireless sensor networks, video image processing technology, automation control system and so on, have obtained certain achievements, which indicates the development of agriculture is gradually transforming to modernization, and realizing real-time refine monitoring, automatic control of agricultural production gradually. This paper has designed a sugarcane growth analysis system to realize real-time monitoring of sugarcane growth and anal- 
ysis of collected data. Experiment results show that users login the system can grasp the crops growth and latest growing environment through network connection of Internet, sensing technology of Internet of Things and the advanced image processing technology, therefore, growers can implement remote visual management and improve their production efficiency.

\section{$7 \quad$ Acknowledgment}

This work is supported the following fund:

2016 The project of improving the basic ability of young teachers in Colleges and universities in Guangxi:"Design and development of electronic commerce platform of agricultural products based on Semantic Technology"(No,KY2016YB455).

2015 college students' innovative training program: "Research on the application of value added travel experience in the mobile terminal of the 'ethnic custom travel' in Guangxi" (No 201511838070);\&\& “The design and development HeYuanTong Campus Mobile Phone APP based on Android" (No 201511838034).Project of scientific research and technology development project of Hezhou: "Design and implementation of agricultural products e-commerce platform based on Semantic Technology" (No,Hekeneng 1506006).

\section{$8 \quad$ References}

[1] B.Q LI, Y.F LING, H.Y ZHANG, S.Y ZHENG: The Design and Realization of Cherry Tomato Harvesting Robot Based on IOT. International Journal of Online Engineering, 12(12), 23, (2016). https://doi.org/10.3991/ijoe.v12i12.6450

[2] B.Q LI, W.L GUAN, S.Y Zheng, X.G Yue: OPTIMISATION DESIGN OF CORN PRECISION SEEDER BASED ON MULTI-ROUTE AND MULTI-CHANNEL CONTROL. Journal of The Balkan Tribological Association, 21(4A), 1215, (2015).

[3] U. A. SHAABAN, M. T. AFIFY, G. E. HASSAN, Z. A. EL-HADDAD: Development of a Vacuum Precision Seeder Prototype for Onion Seeds. Misr J. Ag. Eng, 26(4), 1751, (2009).

[4] B.Q LI, X.M YANG GUAN, S.Y ZHENG : Internet of Things-based Simulation Study on Lijiang River Water Environment Monitoring. Journal of Coastal Research,79, 1-5, (2017).

[5] Y. A. SHAABAN: Development of an Appropriate Pneumatic Planter for Small Holding in Egypt. Colg Agric, Bha Uni, 46(8), 1999, (2010).

[6] P. K. AGARWAL, J. BASCH, L. J. GUIBAS, J. HERSHBERGER, L. ZHANG: Deformable Free Space Tiling for Kinetic Collision Detection. Proc. 4th Wsp Alg Fd. Rbt, 54(3), 245, (2000).

[7] P. K. AGARWAL, J. ERICKSON, L. J. GUIBAS: Kinetic Binary Space Partitions for Intersecting Segments And Disjoint Triangles. Proc. 9th ACM-SIAM , 44(6), 578, (1998).

[8] Z.B. BARUT, A. OZMERZI: Effect of Different Operating Parameters on Seed Holding in the Single Seed Metering Unit of a Pneumatic Planter. Turk. J. Agric, 28, 435, (2004).

[9] M. J. ATALLAH: Some Dynamic Computational Geometry Problems. Comp. Math. Appl, 11(12), 1171 (1985). https://doi.org/10.1016/0898-1221(85)90105-1 
[10] J. BARRAQUAND, J. C. LATOMBE: Robot Motion Planning: A Distributed Representation Approach. Int. J. Rbt. Res, 10, 628, (1991). https://doi.org/10.1177/02783649 9101000604

[11] M. BERN, P. PLASSMANN: Mesh generation. In J.-R. Sack and J. Urrutia, editors, Handbook of Computational Geometry. Els Sci Pub B.V. Ams, 16(4), 566, (2000). https://doi.org/10.1016/B978-044482537-7/50007-3

[12] A. VASS-VARNAI, R. BORNOFF: Thermal Simulations and Measurements - a Combined Approach for Package Characterization. ICEP, Jpn,76(4), 886, (2000).

[13] V. THIYAGARAJAN, K. KALAICHELVAN, K.SRINIVASAN,S. VENUGOPAL, R. VIJAY: Influence of Specific Heat Capacity on Hybrid Non-asbestos Brake Pad Formulation. J. Balkan Tribol. Asc, 10(8), 102, (2015).

[14] L. YANG, X.T. HE, T. CUI, D. X. ZHANG, S. SHI, R. ZHANG, W. MANTAO: Development of Mechatronic Driving System For Seed Meters Equipped on Conventional Precision Corn Planter. Int J Agric \& Biol Eng, 8(4), 1, (2015).

[15] D. KARAYEL, Z.B. BARUT, A. OZMERZI: Mathematical Modeling of

[16] Vacuum Pressure on a Precision Seeder. Byst. Eng, 87(4), 437, (2004).

[17] X.G. YUE, G. ZHANG, Q. WU, F. LI, X.F. CHEN, G.F. REN, M. LI: Wearing Prediction of Stellite Alloys Based on Opposite Degree Algorithm. Rare Metals, 34(4), 125, (2015). https://doi.org/10.1007/s12598-014-0430-0

[18] Z. ZONGMING: Research on Wearing Prediction of the Cylinder Surface Based on Time Series Autoregressive (AR) Model. ICMTMA, Hong Kong, 12(1), 960, (2013). https://doi.org/10.1109/ICMTMA.2013.239

[19] S. SPINU: Numerical Simulation of Viscoelastic Contacts. Part 1. Algorithm Overview. J. Balkan Tribol. Assoc, 10(5), 269, (2015).

\section{Authors}

Li Biqing (1984-),come from Nanning, Guangxi province. master degree, senior engineer, the main research direction for Mobile terminal broadband MINO, IOT. (email: 318281853@qq.com). Li Biqing is with the School of Information and Communication Engineering, Hezhou University, Hezhou Guangxi 542899, China.

Ling Yongfa(1973-), come from Shangyou, Jiangxi province. PhD,professor, the main research direction for Wireless communication network,IOT. (e-mail: janliful@whu.edu.cn). Ling Yongfa is with the School of Information and Communication Engineering, Hezhou University, Hezhou Guangxi 542899, China.

Tian Miao (1984-), come from Zhengzhou, Henan province. Bachelor, assistant experimentalist, the main research direction for the Internet of things. (e-mail: 229292710@qq.com). Tian Miao is with the School of Software, Henan University, Kaifeng Henan 475004, China.

Zheng Shiyong (1983-), come from Guilin, Guangxi province. PhD student, senior engineer, the main research direction for network marketing, IOT. (e-mail: 29291838@qq.com). Zheng Shiyong is with Wuhan University, Wuhan 430070, China.

Article submitted 11 February 2018. Final acceptance 05 March 2018 . Final version published as submitted by the authors. 